\title{
Estimated Open Economy New Keynesian Phillips Curves for the G7
}

\author{
Campbell Leith \\ University of Glasgow
}

\author{
Jim Malley \\ University of Glasgow
}

August 5, 2002

\begin{abstract}
In this paper we develop an open economy model of firms' pricing behaviour under imperfect competition. This allows us to introduce various terms of trade effects influencing the firm's pricing decision, in addition to labour costs which dominate most closed-economy specifications of the New Keynesian Phillips (NKPC) curve. Our analysis gives rise to a hybrid open economy NKPC which nests existing closed and open economy specifications adopted in empirical work. We estimate this specification for the G7 economies and find that the US, UK and Canada typically enjoy less inertia in price setting than the European G7 economies and Japan and that these estimates are both plausible and in line with survey evidence. We also find that the proportion of firms which use simple backward-looking rules of thumb in price setting is greater when the frequency of price change is smaller. Finally there is evidence of significant asymmetries in price setting amongst EMU members.
\end{abstract}

Jel Codes:E3

\section{Introduction}

The New Keynesian Phillips curve (NKPC), which links current inflation to expectations of future inflation and a measure of excess demand in the form of the output gap, has become a mainstay of modern macroeconomics as part of the 'New Neo-Classical Synthesis' (see Goodfriend and King (1997) for a discussion). However, until recently, this essential building block of modern macroeconomics has been criticised on empirical grounds (see Mankiw and Reis (2001), for example), largely because it apparently fails to capture the degree of inflation inertia many believe to be a feature of the data. Recent work on the NKPC based on Calvo's (1983) overlapping contracts framework (see for

\footnotetext{
*We would like to thank Massimiliano Rigon for comments on an earlier draft of this paper. Campbell Leith is also grateful to the ESRC (Grant No.L138251050) for financial assistance in undertaking this research. All errors remain our own.
} 
example Gali and Gertler (1999), Gali et al (2001), Sbordone (2002) and Leith and Malley (2001)) suggests that, as a measure of inflationary pressures, the output gap is a poor proxy for marginal costs. Accordingly, when a theoretically coherent NKPC is estimated for the US and Euro-area, using log-linearised labour share data as a measure of marginal costs, the NKPC appears to be a reasonable model of inflation.

In this paper we build on the insight of this approach, but extend the analysis to take account of open economy terms of trade effects in the determination of output price inflation. More specifically, we construct a model of firms' price setting behaviour which allows firms to sell their products in both home and foreign markets and to substitute imported intermediate goods for domestic labour in production. These extensions imply that we capture two channels through which terms of trade effects may influence the firm's price setting decisions via their impact on marginal costs. Firstly, we allow for changes in demand for domestic products relative to those produced abroad and secondly for changes in the prices of imported intermediate goods relative to other inputs in the production process. In our setup firms will set their prices subject to the constraints implied by Calvo contracts. When firms are able to adjust prices, some will set the new price to maximise the discounted value of future profits, while others will follow a simple backward-looking rule of thumb which, although not optimal in the short-run, will achieve the profit-maximising price in the long-run. The possible existence of rule of thumb price setters may reflect information processing costs along the lines of Sims (1998) and allows us to measure the extent of backward-looking behaviour in price setting. Our formulation gives rise to a specification of the NKPC which nests existing closed and open economy models (see for example, Sbordone (2002), Gali et al (2000 and 2001) and Gali and Salido -Lopez (2001) and Balakrishan and Salido-Lopez (2001)).

When we econometrically estimate our specification of price setting behaviour for the G7 economies we find plausible estimates of the degree of inertia in each economy. Moreover these results suggest that the UK, US and Canada enjoy less inertia than other European members of the G7 and Japan. Our econometric work also suggests that the majority of firms set prices optimally, in a forward-looking manner, rather than following backward-looking rules of thumb. It also appears to be the case that in countries where firms change prices relatively frequently, the proportion of backward-looking price setters increases. This probably reflects the fact that the costs of failing to optimise every reset price are lower when that price is unlikely to remain in force for long. Finally, our results imply that there are significant asymmetries in the degree of pricestickiness among EMU member states as well as asymmetries in the degree of backward-looking behaviour in price setting, which may be a cause for concern for policy makers in the ECB.

The rest of the paper is organised as follows. In Section 2 we derive our open economy NKPC. In Section 3 we estimate the model for the G7 economies. Section 4 contains our conclusions. 


\section{The Model}

In this section we analyse a model of firms' price setting behaviour which takes account of open economy terms of trade effects in two main ways. Firstly, we assume that imperfectly competitive firms sell their goods both at home and abroad and, therefore, that they take into account the price they set relative to the prices set by other firms, both at home and abroad. Secondly, we also assume that firms utilise imported intermediate goods in production so that changes in the price of imported intermediate goods relative to domestic labour costs can affect the marginal costs of production. We further assume that firms face the constraints in price-setting implied by the use of Calvo (1983) contracts, in that they can only change their prices after a random interval of time. Within this constraint, we also allow firms to adopt two forms of price-setting behaviour. Some firms set prices by maximising the expected discounted value of future profits, while the remaining firms choose to follow a simple rule of thumb which updates their prices in line with inflation and the price changes they observed in the previous period.

\subsection{Product Demand}

We first turn to consider the demand for the firm's product ${ }^{1}$. We allow for the possibility that goods produced at home and abroad are not identical in the impact they have on utility. Specifically, we assume that consumers maximise the utility generated by the following consumption bundle,

$$
c_{t}=\left(c_{t}^{d}\right)^{\chi}\left(c_{t}^{f}\right)^{1-\chi}
$$

where, $c_{t}^{d}$ is a CES index of consumer goods produced in the home country, $c_{t}^{d}=\left[\int_{0}^{1} c_{t}^{d}(z)^{\frac{\theta-1}{\theta}} d z\right]^{\frac{\theta}{\theta-1}}$ and $c_{t}^{f}$ is a CES index of consumer goods produced in the foreign country, $c_{t}^{f}=\left[\int_{0}^{1} c_{t}^{f}(z)^{\frac{\theta-1}{\theta}} d z\right]^{\frac{\theta}{\theta-1}}$. There are price indices associated with each of these consumption bundles, such that we can define the index of

\footnotetext{
${ }^{1}$ In doing so it should be borne in mind that there is an implicit model of utility maximisation which allocates an individual's consumption spending across time. This can be the usual consumption Euler equation or can include more complex dynamics, such as those arising from habits effects as in Leith and Malley (2001). However, in analysing firms' pricing decisions, we only require knowledge of how consumer's allocate this consumption spending across domestic and foreign goods.
} 
consumer prices as ${ }^{2}$,

$$
P_{t}=\chi^{-\chi}(1-\chi)^{\chi-1}\left(P_{t}^{d}\right)^{\chi}\left(P_{t}^{f}\right)^{1-\chi} .
$$

The price index associated with the consumer goods produced at home is defined as,

$$
p_{t}^{d}=\left[\int_{0}^{1} p_{t}(z)^{1-\theta} d z\right]^{\frac{1}{1-\theta}}
$$

while the same index for imported goods is given by,

$$
p_{t}^{f}=\varepsilon_{t}\left[\int_{0}^{1} p_{t}^{*}(z)^{1-\theta} d z\right]^{\frac{1}{1-\theta}} .
$$

The Cobb-Douglas form of the aggregate utility function implies relative shares of home and foreign goods in consumption given by, $c_{t}^{d}=\chi \frac{P_{t}}{P_{t}^{d}} c_{t}$, and $c_{t}^{f}=(1-\chi) \frac{P_{t}}{P_{t}^{f}} c_{t}$. There are corresponding equations for the foreign economy, where foreign variables are denoted by a ' $*$ '. If we assume that the government allocates spending across goods in the same pattern as consumers then the total demand for domestically produced goods for the purposes of domestic and foreign public and private consumption are given by the sum of the following demands,

$$
\begin{aligned}
c^{d}{ }_{t} & =\chi \frac{P_{t}}{p_{t}^{d}} c_{t}, \text { and, } g^{d}{ }_{t}=\chi \frac{P_{t}}{p_{t}^{d}} g_{t} \\
c^{f *}{ }_{t} & =(1-\chi) \frac{P_{t}}{p_{t}^{f}} c_{t}^{*}, \text { and, } g^{f *}{ }_{t}=(1-\chi) \frac{P_{t}}{p_{t}^{f}} g_{t}^{*} .
\end{aligned}
$$

There is an additional source of demand for domestically produced goods - we assume that foreign firms utilise a bundle of domestically produced goods in production, just as domestic firms employ a bundle of foreign produced goods in domestic production. Accordingly, we define $m(i)_{t}^{f *}=\left[\int_{0}^{1}\left(m(i, z)_{t}^{f *}\right)^{\frac{\theta-1}{\theta}} d z\right]^{\frac{\theta}{\theta-1}}$ as being the bundle of domestically produced products used in foreign production, by foreign firm $i$. As this composite intermediate good possesses the same degree of substitutability between goods as the government and consumers' consumption bundles, foreign firms, domestic consumers and foreign consumers will

\footnotetext{
${ }^{2}$ This price index is derived by minimising the cost of purchasing a single unit of the composite consumption bundle, $c_{t}$. The Cobb-Douglas form of the utility function implies that to minimise costs consumers will allocate spending across the home and foreign goods in the following patter, $P_{t}^{f} c_{t}^{f}=\frac{\chi}{1-\chi} P_{t}^{d} c_{t}^{d}$. Utilising the fact that $c_{t}=\left(c_{t}^{d}\right)^{\chi}\left(c_{t}^{f}\right)^{1-\chi}=1$ allows us to eliminate $c_{t}^{f}$ from this relationship and solve in terms of $c_{t}^{d}=\left(\frac{\chi}{1-\chi} \frac{P_{t}^{d}}{P_{t}^{f}}\right)^{-\chi}$.
} The consumer price level is then defined as, $P_{t}=P_{t}^{f}\left(c_{t}^{d}\right)^{\frac{\chi-1}{\chi}}+P_{t}^{d} c_{t}^{d}$. Replacing $c_{t}^{d}$ in this expression yields the consumer price index defined above. 
allocate their demand across domestic goods in the same pattern, such that,

$$
y(z)_{t}=\left(\frac{p(z)_{t}}{p_{t}^{d}}\right)^{-\theta}\left(c_{t}^{d}+g_{t}^{d}+m_{t}^{f *}+c_{t}^{f *}+g_{t}^{f *}\right)
$$

where $m_{t}^{f *}=\int_{0}^{1} \frac{p(z)_{t}}{p_{t}^{d}} m_{t}^{f *}(z) d z$ is the average demand for home country produced goods for use in foreign firms' production. The demand for the firm's product depends upon its price relative to the prices of other domestic producers, as well as the amount of domestic and foreign, public and private consumption and intermediate good demand allocated to domestically produced goods where these proportions depend on the relative prices detailed in (5). Therefore, we are allowing for substitution in demand between goods produced at home and abroad in describing the demand for the representative domestic firm's product.

\section{$2.2 \quad$ Imported Intermediate Goods}

We now turn to consider the second channel through which we introduce open economy effects into the firm's pricing decision, by considering a production function which includes imported intermediate goods as a factor of production,

$$
y(z)_{t}=\left(\alpha_{N} N(z)_{t}^{\frac{\rho-1}{\rho}}+\alpha_{m}\left(m(z)_{t}^{f}\right)^{\frac{\rho-1}{\rho}}\right)^{\frac{\rho}{\rho-1} / \psi} \bar{K}^{1-\frac{1}{\psi}}
$$

where $N(z)_{t}$ and $m(z)_{t}^{f}$ are the labour input and imported intermediate goods used in production. We model these inputs as imperfect substitutes and $\rho$ measures the elasticity of substitution between them. Firms also possess a stock of capital, $\bar{K}$, which is assumed, for simplicity, to be fixed and $1-\frac{1}{\psi}$ describes the weight given to capital in production. Here the first-order conditions for cost minimisation are given by,

$$
N(z)_{t}=\left(y(z)_{t}\right)^{\psi}\left(\alpha_{N}+\alpha_{m}\left(\frac{W_{t}}{p_{t}^{f}} \frac{\alpha_{m}}{\alpha_{N}}\right)^{\rho-1}\right)^{\frac{-\rho}{\rho-1}} \bar{K}^{\psi-1}
$$

and,

$$
m(z)_{t}^{f}=\left(y(z)_{t}\right)^{\psi}\left(\alpha_{N}\left(\frac{W_{t}}{p_{t}^{f}} \frac{\alpha_{m}}{\alpha_{N}}\right)^{1-\rho}+\alpha_{m}\right)^{\frac{-\rho}{\rho-1}} \bar{K}^{\psi-1}
$$

which together reveal the cost-minimising combination of labour and intermediate goods,

$$
\left(\frac{N(z)_{t}}{m(z)_{t}^{f}}\right)=\left(\frac{W_{t}}{p_{t}^{f}} \frac{\alpha_{m}}{\alpha_{N}}\right)^{-\rho}
$$


so that changes in the price of imported intermediate goods relative to labour costs will result in a substitution between labour and intermediate import goods. This can then be substituted back into the production function to obtain,

$$
N(z)_{t}=\left(y(z)_{t}\right)^{\psi}\left(\alpha_{N}+\alpha_{m}\left(\frac{W_{t}}{p_{t}^{f}} \frac{\alpha_{m}}{\alpha_{N}}\right)^{\rho-1}\right)^{\frac{-\rho}{\rho-1}}
$$

and,

$$
m(z)_{t}^{f}=\left(y(z)_{t}\right)^{\psi}\left(\alpha_{N}\left(\frac{W_{t}}{p_{t}^{f}} \frac{\alpha_{m}}{\alpha_{N}}\right)^{1-\rho}+\alpha_{m}\right)^{\frac{-\rho}{\rho-1}} .
$$

We can next consider the definition of marginal cost for firm $z$,

$$
M C(z)_{t}=\frac{W_{t}}{P_{t}} \frac{\partial N(z)_{t}}{\partial y(z)_{t}}+\frac{p_{t}^{f}}{P_{t}} \frac{\partial m(z)_{t}^{f}}{\partial y(z)_{t}}
$$

and after substituting for $\frac{\partial N(z)_{t}}{\partial y(z)_{t}}$ and $\frac{\partial m(z)_{t}^{f}}{\partial y(z)_{t}}$ (from equations 11 and 12) we can decompose marginal cost into two elements - one which is independent of the firms actions and the other which depends upon the position they are operating on their production function, such that marginal cost equals,

$$
\begin{aligned}
M C(z)_{t} & =\left(y(z)_{t}\right)^{\psi-1}\left[\begin{array}{l}
\frac{W_{t}}{P_{t}}\left(\alpha_{N}+\alpha_{m}\left(\frac{W_{t}}{p_{t}^{f}} \frac{\alpha_{m}}{\alpha_{N}}\right)^{\rho-1}\right)^{\frac{-\rho}{\rho-1}} \\
+\frac{p_{t}^{f}}{P_{t}}\left(\alpha_{N}\left(\frac{W_{t}}{p_{t}^{f}} \frac{\alpha_{m}}{\alpha_{N}}\right)^{1-\rho}+\alpha_{m}\right)^{\frac{-\rho}{\rho-1}}
\end{array}\right] \\
& =\left(y(z)_{t}\right)^{\psi-1} \widetilde{M C}_{t} .
\end{aligned}
$$

The first multiplicative term captures the increase in firm specific marginal costs through increasing production given the fixed stock of capital ${ }^{3}$ and decreasing marginal returns to the remaining factors. The second element reflects the labour and intermediate goods costs that enter into the costs of production and are constant across firms. We label this second term, $\widetilde{M C}_{t}$.

\subsection{Profit Maximising Price Setting}

We can now start to consider the problem facing a firm which chooses to set its price in order to maximise profits. The real variable profits ${ }^{4}$ (deflated by

\footnotetext{
${ }^{3}$ An alternative modelling strategy would be to allow capital to be reallocated across firms so as to equate the shadow value of capital, implying that each firm's marginal cost is identical to the economy-wide average cost (see Sbordone (2002) for a discussion). However, the possibility that firms can reallocate capital without friction, but cannot reset prices continuously seems implausible.

${ }^{4}$ We ignore the fixed costs of utilising the capital stock in formulating the firm's problem and we assume that all shocks are sufficiently small that firms continue to earn positive profits at all points in time.
} 
the consumer prices, since the firms are assumed to be owned by domestic consumers) in period $t$ of the firm producing good $z$ are given by,

$$
\frac{p(z)_{t}}{P_{t}} y(z)_{t}-\frac{W_{t}}{P_{t}} N_{t}-\frac{p_{t}^{f}}{P_{t}} m_{t}^{f}
$$

Such firms are able to change their price with probability $\alpha$ in a given period, so that $\frac{1}{1-\alpha}$ measures the length of time a price contract is expected to exist. This allows us to write the problem facing a firm which is able to change prices in period $t$ as,

$$
\begin{aligned}
& \left(\frac{x_{t}}{p_{t}^{d}}\right)^{-\theta}\left(c_{t}^{d}+g_{t}^{d}+m_{t}^{f *}+c_{t}^{f *}+g_{t}^{f *}\right) \frac{x_{t}}{P_{t}} \\
& -\widetilde{M C_{t}}\left(\frac{x_{t}}{p_{t}^{d}}\right)^{-\theta \psi}\left(c_{t}^{d}+g_{t}^{d}+m_{t}^{f *}+c_{t}^{f *}+g_{t}^{f *}\right)^{\psi} \\
& +E_{t} \sum_{s=1}^{\infty} \frac{(\alpha)^{s}\left[\frac{\left(\frac{x_{t}}{p_{t+s}^{d}}\right)^{-\theta}\left(c_{t+s}^{d}+g_{t+s}^{d}+m_{t+s}^{f *}+c_{t+s}^{f *}+g_{t+s}^{f *}\right) \frac{x_{t}}{P_{t+s}}}{-\widetilde{M C}_{t+s}\left(\frac{x_{t}}{p_{t+s}^{d}}\right)^{-\theta \psi}\left(c_{t+s}^{d}+g_{t+s}^{d}+m_{t+s}^{f *}+c_{t+s}^{f *}+g_{t+s}^{f *}\right)^{\psi}}\right]}{\prod_{j=1}^{s} r_{t+j-1}}
\end{aligned}
$$

The first order condition for this optimisation is given by,

$$
\begin{gathered}
\psi \theta\left(p_{t}^{d}\right)^{\psi \theta} \widetilde{M C_{t}}\left(c_{t}^{d}+g_{t}^{d}+m_{t}^{f *}+c_{t}^{f *}+g_{t}^{f *}\right)^{\psi} \\
\left(x_{t}\right)^{1+\theta(\psi-1)}=\frac{+E_{t} \sum_{s=1}^{\infty} \frac{\alpha_{p}^{s}\left(\theta \psi\left(p_{t+s}^{d}\right)^{\psi \theta} W_{t+s}\left(c_{t+s}^{d}+g_{t+s}^{d}+m_{t+s}^{f *}+c_{t+s}^{f *}+g_{t+s}^{f *}\right)^{\psi}\right)}{\prod_{j=1}^{s} r_{t+j-1}}}{(\theta-1)\left(p_{t}^{d}\right)^{\theta} P_{t}^{-1}\left(c_{t}^{d}+g_{t}^{d}+m_{t}^{f *}+c_{t}^{f *}+g_{t}^{f *}\right)} \\
+E_{t} \sum_{s=1}^{\infty} \frac{\alpha_{p}^{s}(\theta-1)\left(p_{t+s}^{d}\right)^{\theta} P_{t+s}^{-1}\left(c_{t+s}^{d}+g_{t+s}^{d}+m_{t+s}^{f *}+c_{t+s}^{f *}+g_{t+s}^{f *}\right)}{\prod_{j=1}^{s} r_{t+j-1}}
\end{gathered}
$$

The first-order condition for the optimal price can be log-linearised to yield,

$$
\begin{aligned}
\left(\frac{(1+\theta(\psi-1)) \bar{r}}{\bar{r}-\alpha_{p}}\right) \widehat{x}_{t}= & \widehat{\widehat{M C}_{t}}+(\psi-1) \widehat{\widetilde{y}}_{t}+\widehat{P}_{t}+\theta(\psi-1) \widehat{p}_{t}^{d} \\
& +\sum_{s=1}^{\infty}\left(\frac{\alpha_{p}}{\bar{r}}\right)^{s} E_{t}\left[\widehat{\widehat{M C}}_{t+s}+(\psi-1) \widehat{\widetilde{y}}_{t+s}+\widehat{P}_{t+s}+\theta(\psi-1) \widehat{p}_{t+s}^{d}\right]
\end{aligned}
$$

where $\widetilde{y}_{t}=c_{t}^{d}+g_{t}^{d}+m_{t}^{f *}+c_{t}^{f *}+g_{t}^{f *}$ is the average firm output supplying domestic and foreign, private and public demand. This infinite forward summation, can also be quasi-differenced to give a first order difference equation describing the evolution of the optimal price set by profit-maximising firms,

$$
\left(\frac{\alpha}{\bar{r}-\alpha}\right) E_{t} \widehat{x}_{t+1}=\left(\frac{\bar{r}}{\bar{r}-\alpha}\right) \widehat{x}_{t}-\widehat{\widehat{M C}}_{t}-(\psi-1) \widehat{\widetilde{y}}_{t}-\widehat{P}_{t}-\theta(\psi-1) \widehat{p}_{t}^{d} .
$$

The firms which do not perform this optimisation, instead follow a rule of thumb whereby they set a price equal to the average price set on the previous 
period after scaling this up by the rate of inflation observed in the previous period. Therefore, the log-linearised index of output prices is given by,

$$
\widehat{p}_{t}^{d}=\alpha \widehat{p}_{t-1}^{d}+(1-\alpha) \widehat{p}_{t}^{r}
$$

where $p_{t}^{r}$ is the average reset price in period $t$ and is given by,

$$
\widehat{p}_{t}^{r}=(1-\omega) \widehat{x}_{t}+\omega \widehat{p}_{t}^{b}
$$

$\omega$ is the proportion of firms following the rule of thumb, and $p_{t}^{b}$ is the price set set according to the rule of thumb,

$$
\widehat{p}_{t}^{b}=\widehat{p}_{t-1}^{r}+\widehat{\pi}_{t-1}^{d} .
$$

Substituting equation (22) into (21) gives,

$$
\widehat{p}_{t}^{r}=(1-\omega) \widehat{x}_{t}+\omega \widehat{p}_{t-1}^{r}+\omega \widehat{p}_{t-1}^{d}-\omega \widehat{p}_{t-2}^{d} .
$$

Inserting equation (20) into this expression then yields,

$$
\begin{aligned}
\frac{\widehat{p}_{t}^{d}}{1-\alpha}-\frac{\alpha \widehat{p}_{t-1}^{d}}{1-\alpha}= & (1-\omega) \widehat{x}_{t}+\omega\left(\frac{\widehat{p}_{t-1}}{1-\alpha}-\frac{\alpha \widehat{p}_{t-2}}{1-\alpha}\right) \\
& +\omega \widehat{p}_{t-1}-\omega \widehat{p}_{t-2} .
\end{aligned}
$$

This can be rearranged in terms of $\widehat{x}_{t}$, substituted into equation (22) and solved using the definition of output price inflation, $\widehat{\pi}_{t}=\widehat{p}_{t}^{d}-\widehat{p}_{t-1}^{d}$ to give,

$$
\begin{aligned}
\widehat{\pi}_{t}^{d}= & \frac{\beta \alpha}{\lambda} E_{t} \widehat{\pi}_{t+1}^{d}+\frac{\omega}{\lambda} \widehat{\pi}_{t-1}^{d}+\frac{(1-\omega)(1-\alpha)(1-\alpha \beta)}{(1+(\psi-1) \theta) \lambda}\left(\widehat{\widetilde{M C}}_{t}\right. \\
& \left.+(\psi-1) \widehat{\widetilde{y}}_{t}+\widehat{P}_{t}-\widehat{p}_{t}^{d}\right) .
\end{aligned}
$$

where $\lambda=\omega+\beta \omega \alpha+\alpha-\omega \alpha$.

\subsection{Open Economy NKPC}

We next reformulate the above specification in a form more appropriate for estimation. To do so consider the element of marginal cost which is independent of the firm's actions,

$$
\widetilde{M C_{t}}=\frac{W_{t}}{P_{t}}\left(\alpha_{N}+\alpha_{m}\left(\frac{W_{t}}{p_{t}^{f}} \frac{\alpha_{m}}{\alpha_{N}}\right)^{\rho-1}\right)^{\frac{-\rho}{\rho-1}}+\frac{p_{t}^{f}}{P_{t}}\left(\alpha_{N}\left(\frac{W_{t}}{p_{t}^{f}} \frac{\alpha_{m}}{\alpha_{N}}\right)^{1-\rho}+\alpha_{m}\right)^{\frac{-\rho}{\rho-1}} .
$$

This can be log-linearised as,

$$
\widehat{\widehat{M C}}_{t}=\frac{\bar{w}}{\left(\bar{w}+\frac{\bar{p}^{f}}{\bar{P}}\left(\bar{w}^{f} \frac{\alpha_{m}}{\alpha_{N}}\right)^{\rho}\right)} \widehat{w}_{t}+\frac{\frac{\bar{p}^{f}}{\bar{P}}\left(\bar{w}^{f} \frac{\alpha_{m}}{\alpha_{N}}\right)^{\rho}}{\left(\bar{w}+\frac{\bar{p}^{f}}{\bar{P}}\left(\bar{w}^{f} \frac{\alpha_{m}}{\alpha_{N}}\right)^{\rho}\right)}\left(\widehat{p}_{t}^{f}-\widehat{P}_{t}\right)
$$


which allows us to rewrite the Phillips curve as,

$$
\begin{aligned}
\widehat{\pi}_{t}^{d}= & \frac{\beta \alpha}{\lambda} E_{t} \widehat{\pi}_{t+1}^{d}+\frac{\omega}{\lambda} \widehat{\pi}_{t-1}^{d}+\frac{(1-\omega)(1-\alpha)(1-\alpha \beta)}{(1+(\psi-1) \theta) \lambda}\left(\frac{\bar{w}}{\left(\bar{w}+\frac{\bar{p}^{f}}{\bar{P}}\left(\bar{w}^{f} \frac{\alpha_{m}}{\alpha_{N}}\right)^{\rho}\right)}\right. \\
& \left.\left(\widehat{W}_{t}-\widehat{p}_{t}^{d}\right)+\frac{\frac{\bar{p}^{f}}{\bar{P}}\left(\bar{w}^{f} \frac{\alpha_{m}}{\alpha_{N}}\right)^{\rho}}{\left(\bar{w}+\frac{\bar{p}^{f}}{\bar{P}}\left(\bar{w}^{f} \frac{\alpha_{m}}{\alpha_{N}}\right)^{\rho}\right)}\left(\widehat{p}_{t}^{f}-\widehat{p}_{t}^{d}\right)+(\psi-1) \widehat{\widetilde{y}}_{t}\right) .
\end{aligned}
$$

Here we can see the impact of introducing open economy considerations to the firm's pricing problem. Firstly, marginal costs largely reflect labour costs, $\widehat{W}_{t}-\widehat{p}_{t}^{d}$, as they do in the closed economy case. However, the weight on labour costs in the marginal cost term reflects the steady-state share of labour costs in total variable costs (labour plus intermediate goods) which, in turn, depends on the substitutability of these two factors. Additionally, the costs of intermediate goods relative to domestic prices, $\widehat{p}_{t}^{f}-\widehat{p}_{t}^{d}$, also affects the marginal costs of production. Finally, the level of output at the individual firm level also affects marginal costs, due to decreasing marginal returns in the two factors which are variable in the short-run. This effect is captured in the term $(\psi-1) \widehat{\widetilde{y}}_{t}$. However, here $\widehat{\widetilde{y}}_{t}$ refers to average firm output and not GDP due to the use of intermediate goods in production, which means we need to examine the link between average firm output and GDP. We also wish to consider the link between the open economy definition of marginal cost and the labour share proxy commonly considered in the closed economy estimations of the NKPC to facilitate comparison with existing studies. This is done in Appendix I, where the open economy NKPC is shown to be,

$$
\begin{aligned}
\widehat{\pi}_{t}^{d}= & \frac{\beta \alpha}{\lambda} E_{t} \widehat{\pi}_{t+1}^{d}+\frac{\omega}{\lambda} \widehat{\pi}_{t-1}^{d}+\frac{(1-\omega)(1-\alpha)(1-\alpha \beta)}{(1+(\psi-1) \theta) \lambda}\left(\widehat{s}_{t}\right. \\
& -(\psi-1)\left(\frac{\frac{\bar{p}^{f} \bar{m}^{f}}{\bar{p}^{d} \bar{y}}}{1+(1-\psi) \frac{\bar{p}^{f} \bar{m}^{f}}{\bar{p}^{d} \bar{y}}}\right) \widehat{y}_{t} \\
& -\left((1-\rho)\left(\frac{\frac{\bar{p}^{f} \bar{m}^{f}}{\bar{p}^{d} \bar{y}}}{\bar{s}+\frac{\bar{p}^{f} \bar{m}^{f}}{\bar{p}^{d} \bar{y}}}\right)+\rho\left(\frac{\frac{\bar{p}^{f} \bar{m}^{f}}{\bar{p}^{d} \bar{y}}}{1+(1-\psi) \frac{\bar{p}^{f} \bar{m}^{f}}{\bar{p}^{d} \bar{y}}}\right)\left(\frac{\bar{s}}{\bar{s}+\frac{\bar{p}^{f} \bar{m}^{f}}{\bar{p}^{d} \bar{y}}}\right)\right) \\
& \left.\left(\widehat{W}_{t}-\widehat{p}_{t}^{f}\right)+\left(\frac{\frac{\bar{p}^{f} \bar{m}^{f}}{\bar{p}^{d} \bar{y}}}{1+(1-\psi) \frac{\bar{p}^{f} \bar{m}^{f}}{\bar{p}^{d} \bar{y}}}\right)\left(\widehat{p}_{t}^{d}-\widehat{p}_{t}^{f}\right)\right) .
\end{aligned}
$$

where

$$
\widehat{s}_{t}=\widehat{W}_{t}-\widehat{P}_{t}+\widehat{N}_{t}-\widehat{y}_{t}-(1-\chi)\left(\widehat{p}_{t}^{d}-\widehat{p}_{t}^{f}\right)
$$

is the labour share variable ${ }^{5}$. The terms of trade effects entering from the substitutability between home and foreign goods in consumption is actually

\footnotetext{
${ }^{5}$ By substituting the definition of consumer prices (2) into this definition, the labour share variable can be rewritten as $\widehat{s}_{t}=\widehat{W}_{t}+\widehat{N}_{t}-\widehat{p}_{t}^{d}-\widehat{y}_{t}$ which does not include the parameter $\chi$
} 
contained in the labour share variable as this captures the distinction between product and consumption wages which does not arise in the closed economy case. In the usual closed economy estimates of the Phillips curve, the log-linearised labour share, $\widehat{s}_{t}$, with $\chi=1$ (i.e. no international trade) is the appropriate measure of marginal cost. In the open economy case care must be made to maintain the distinction between consumption and product wages in defining the labour share variable. This measure of marginal cost is augmented by a term in the output gap $\widehat{y}_{t}$ which captures the rise in marginal costs when output is above equilibrium given decreasing marginal returns in the variable factors of production. It also includes a term in the price of labour relative to import prices, $\widehat{W}_{t}-\widehat{p}_{t}^{f}$ which reflects the possibility of substituting between labour and imported goods in production. There is also a straight terms of trade term, $\widehat{p}_{t}^{d}-\widehat{p}_{t}^{f}$, which comes from the definition of GDP in the presence of intermediate goods.

It should be noted that this specification nests the estimation of NKPCs in other papers. For example, removing all the open economy elements (by ignoring all international trade in final goods, $\chi=1$, and by assuming that $\frac{\bar{p}^{f} \bar{m}^{f}}{\bar{p}^{d} \bar{y}}=0$, such that no imported intermediate goods are used in production), would return us to the closed-economy specifications of among others, Sbordone (2002), Gali et al (2000 and 2001) which include estimates for the US and Euro-area. By only allowing trade in intermediate goods, but not final goods, this reduces to the open economy specifications estimated for Spain by Gali and Lopez-Salido (2001) and for the UK in Balakrishnan and Lopez-Salido (2001). In contrast, in this paper we have developed a model which includes substitution not only between labour and imported goods in production, but also between domestic and foreign goods in consumption. We now turn to estimate our open economy NKPC for the G7 economies.

\section{Estimation and Empirical Results}

In this Section we estimate the 'deep parameters' of the model derived in Section 2 for the G7 over the period 1960(1) to $1999(4)^{6}$. These include the subjective rate of time preference, $\beta$, the probability that a firm can reset their price in period $t, \alpha$, the proportion of firms following rule of thumb pricing behaviour in time $t, \omega$ and the parameter measuring the elasticity of substitution between labour and imported intermediate goods, $\rho$. We also examine the robustness of these estimates and discuss them in the context of findings from other partial and general equilibrium studies. This discussion allows us to draw a number of conclusions of direct relevance to policy makers.

and is, therefore, applicable no matter how open the economy. This is the definition we shall use in our empirical work below.

${ }^{6}$ Further detail on sources and methods is reported in the Appendix II. 


\subsection{Empirical Considerations and Estimator}

Prior to estimating (29) for the G7 economies it is necessary to obtain data for the steady-state ratio of imported goods used in production relative to GDP, $\frac{\bar{p}^{f} \bar{m}^{f}}{\bar{p}^{d} \bar{y}}$, and the steady-state labour share $\bar{s}$. It is readily apparent from the data that the ratio of imported intermediate goods relative to GDP has been growing in line with the ratio of imports to GDP. Accordingly, estimating an open economy NKPC assuming that the importance of imports in production was constant, would imply too great a weight on open economy effects in the 1970 s and too small a weight in the 1990s, ceteris paribus. To account for this we replace this ratio with actual data rather than an average across the sample. This has the desired effect of appropriately capturing the increasing importance of imported goods in production over time. For consistency we also use actual data for the labour share and in calibrating $\psi$ to calculate the weights on the open economy terms in our $\mathrm{NKPC}^{7}$. To obtain the latter, consider the labour and intermediate goods share under imperfect competition,

$$
\frac{\overline{W N}+\bar{p}^{f} \bar{m}^{f}}{\bar{p}^{d} \overline{\widetilde{y}}}=\frac{\theta}{\psi(\theta-1)}
$$

which, by noting the definition of GDP can be used to derive an estimate of $\psi$ from labour share and imported intermediate goods data,

$$
\psi=\frac{\theta}{(\theta-1)} /\left(\frac{\bar{s}+\frac{\bar{p}^{f} \bar{m}^{f}}{\bar{p}^{d} \bar{y}}}{1+\frac{\bar{p}^{f} \bar{m}^{f}}{\bar{p}^{d} \bar{y}}}\right) .
$$

To calculate $\psi$ and when estimating (29) we follow the literature and adopt values for the elasticity of demand facing the firm, $\theta$. The parameter, $\theta$ implies a mark-up of prices over marginal costs, $\mu$ of $\frac{\theta}{\theta-1}$ which we assume to be $10 \%$, so that $\theta=11$. We also consider the robustness of our results to changing this assumed parameter by reducing $\theta$ to 3.5 which implies a mark-up of $40 \%^{8}$. Note that this is a similar range of values to those considered in Gali et al (2001) and encompasses the values adopted in the literature.

Given that our model incorporates forward looking rational expectations (RE), we employ Hansen's (1982) generalised method of moments (GMM) estimator which easily handles the set of orthogonality conditions suggested by the RE hypothesis. In this context and incorporating time-varying measures of $\frac{\bar{p}^{f} \bar{m}^{f}}{\bar{p}^{d} \bar{y}}, \bar{s}$ and $\psi$ discussed above, our econometric specification can be expressed as follows,

$$
E_{t}\left(\left[\widehat{\pi}_{t}^{d}-\frac{\beta \alpha}{\lambda} E_{t} \widehat{\pi}_{t+1}^{d}-\frac{\omega}{\lambda} \widehat{\pi}_{t-1}^{d}-\frac{(1-\omega)(1-\alpha)(1-\alpha \beta)}{\left(1+\left(\psi_{t}-1\right) \theta\right) \lambda}\left(\widehat{M C}_{t}\right)\right] \mathbf{z}_{t}\right)=0
$$

\footnotetext{
${ }^{7}$ However, we also considered the implications for our results of adopting straightforward averages for these ratios and these are discussed below.

${ }^{8}$ See Appendix III for detailed results.
} 
where

$$
\begin{aligned}
& \widehat{M C}_{t}= \widehat{s}_{t}-\left(\psi_{t}-1\right)\left(\frac{i_{t}^{s}}{1+\left(1-\psi_{t}\right) i_{t}^{s}}\right) \widehat{y}_{t}- \\
&\left((1-\rho)\left(\frac{i_{t}^{s}}{s_{t}+i_{t}^{s}}\right)+\rho\left(\frac{i_{t}^{s}}{1+\left(1-\psi_{t}\right) i_{t}^{s}}\right)\left(\frac{s_{t}}{s_{t}+i_{t}^{s}}\right)\right)\left(\widehat{W}_{t}-\widehat{p}_{t}^{f}\right) \\
&+\left(\frac{i_{t}^{s}}{1+\left(1-\psi_{t}\right) i_{t}^{s}}\right)\left(\widehat{p}_{t}^{d}-\widehat{p}_{t}^{f}\right) \\
& \psi_{t}=\frac{\mu}{\left(W_{t} N_{t} / p_{t}^{d} y_{t}\right)+i_{t}^{s}} /\left(1+i_{t}^{s}\right) ; i_{t}^{s}=\frac{p_{t}^{f} m_{t}^{f}}{p_{t}^{d} y_{t}} ; \lambda=\omega+\beta \omega \alpha+\alpha-\omega \alpha ; \mathbf{z}_{t} \text { is a vector }
\end{aligned}
$$
of instruments ${ }^{9}$, including 4 lags of demeaned price inflation, $\widehat{\pi}^{d}$, wage inflation, $\widehat{\pi}^{w}$, commodity price inflation, $\widehat{\pi}^{c}$, the labour share, $\widehat{s}$ the output gap, $\widehat{y}$ and a constant term; all other variables are defined as in Section 2. Further note that hatted rates are calculated as deviations away from a constant mean and hatted levels and relative prices are calculated as deviations away from a quadratic trend $^{10}$. Finally we assume that $E_{t}\left(\mathbf{z}_{t}, \mathbf{u}_{t}\right)=0$.

\subsection{Interpretation of Results}

We next turn to the GMM estimates of (33). Table 1 gives the results for our central estimates of the NKPC across four model variants. Model $M_{1}$ represents the closed-economy estimates which are comparable with the figures for the US in Gali et al (op. cit.). $M_{2}$ introduces the open economy effects considered above and freely estimates, $\rho$, the elasticity of substitution between imports used in production and labour. As for all economies, except the US, this coefficient is not significantly different from 1 . In model $M_{3}$ we replace the CES production function with a Cobb-Douglas formulation by imposing $\rho=1$. Finally, in variant $M_{4}$ we reduce the elasticity of substitution between imported production imports and labour to $1 / 3$ in line with the assumption of McCallum (2001).

If we consider the closed economy estimates first, we can see the estimates of the degree of nominal inertia, $\alpha$, and the proportion of firm's which follow backward-looking rules of thumb, $\omega$ are all highly significantly and economically plausible. We can estimate the average time it takes for all prices to adjust in an economy as $\frac{1}{1-\alpha}$ and this implies that the country with least inertia is Italy with average price adjustment taking only 6 months, closely followed by the US at 6.5 months, the UK at just under 7 months, Canada at slightly less than 9 months,

\footnotetext{
${ }^{9}$ Our instruments set is based on the one used in Galí and Gertler (1999). We conduct Hansen's J-test below to test the validity of our overidentifying restrictions since we have more instruments than parameters to estimate.

${ }^{10}$ Both these transformations are common in this literature, see e.g. Gali et al (1999 and 2001). The rates include: $\pi^{p}, \pi^{w}, \pi^{c}$ and, $s$ and the levels and relative prices include: $y$, $W-p^{f}$ and $p^{d}-p^{f}$.
} 
Japan at 9 months, France at just over 9 months and Germany being an outlier with the longest time between price adjustment across all firms in the economy of close to 2 years. The ranking of economies according to the estimated degree of inertia is not implausible with the US, UK and Canada in general possessing a greater degree of price flexibility than the European economies within the G7 or Japan. The apparent degree of price flexibility in Italy is perhaps more surprising, especially when compared with other EMU members. However, in Italy the proportion of firms adopting backward-looking rules of thumb is the highest at 39\% and so these estimates possibly reflect the existence of indexation mechanisms rather than genuine price flexibility. In relation to other studies the estimates for the US are in line with other studies in the literature such as, for example, Gali et al (op. cit.), and Leith and Malley (op. cit.). The figures for Canada are also consistent with those reported in Gagnon and Kahn (2001).

The estimates of the degree of backward-looking behaviour also vary across the G7 economies, ranging from $6 \%$ of firms in the UK to $39 \%$ in Italy. It also appears, with the exception of the UK, that the less frequently a country changes prices then the more likely firms are to use backward-looking rules of thumb. This probably reflects the information gathering costs implicit in setting a profit-maximising price and the costs of failing to maximise profits. If firms only change prices infrequently then they will use all available information to set that price carefully when the opportunity arises, while with less nominal inertia there are less costs involved in setting a rule of thumb price. The estimates of $\beta$ are in line with other studies, although as a measure of consumers' rate of time preference they are slightly low, probably reflecting the extent to which firms discount the future to take account of elements of risk not formally included in our model.

When we introduce the open economy elements in model $M_{2}$ then this does not significantly alter the estimates of the consumers' discount factor, $\beta$ the probability of price adjustment, $\alpha$, and the proportion of backward-looking price setters, $\omega$ (see column 1 of Tables 2 and 3 for the t-stats associated with testing the null that the $\alpha$ 's and $\omega$ 's estimated in the open economy specification are significantly different from those estimated in model $M_{2}$ ). The countries in which introducing open economy aspects makes the greatest difference are Canada and France and to a lesser extent Italy and the UK. A relatively closed economy, such as the US, experiences no change in the estimated degree of price inertia at all through adding open economy considerations. These differences translate into an increase in the estimate of the average time for all firms to adjust their prices in Canada from 9 to 11 months. However, it must be stressed that this difference is not statistically significant, and the changes in other countries are even smaller. The estimated proportion of rule of thumb price setters is also largely invariant to introducing open economy effects - the estimated proportion of backward-looking price setters, changes by less than $3 \%$, with most countries experiencing far smaller changes. Again, these changes are insignificant in statistical terms.

In $M_{3}$ we consider the impact of imposing a Cobb-Douglas form of production function by setting the elasticity of substitution between labour and 
imported intermediate goods, $\rho$, to 1 . This restriction is a valid restriction on the freely estimated values of $\rho$ for all countries except the US. Again imposing the Cobb-Douglas form in our open economy model has no significant effect on the estimated parameters of the model. Finally, in $M_{4}$ we impose a lower elasticity of substitution between imported intermediate goods and labour in production of $1 / 3$. This is consistent with the value imposed in McCallum (2001) and severely limits the extent to which labour can be substituted for imported goods in production in response to price changes (and therefore limits the extent to which firms can insulate marginal costs from changes in the price of imports used in production). Imposing this elasticity, significantly reduces the estimated time period of price adjustment in Germany, and the proportion of backward-looking price setting in Italy. It has a negligible and insignificant impact on other parameters estimates for other countries. This change brings the estimate of inertia in Germany closer to the estimates for other countries in our sample and increases the estimated level of backward-looking behaviour to $50 \%$ in the case of Italy. However, we also see from Table 4, that imposing this value of $\rho$ is not a valid parameter restriction on the freely estimated $\rho$ in the case of Italy and the US, but is for the other G7 economies. In other countries imposing this elasticity of substitution does not significantly affect the estimates of the degree of nominal inertia. Our results therefore appear to suggest that introducing open economy considerations to the NKPC does not significantly affect the estimated degrees of nominal inertia and backward-looking behaviour for the G7 economies. Of course, this does not imply that analysis of the impact of monetary and fiscal policy need only consider closed economy models. In a general equilibrium context, open economy factors could have a significant impact through the endogenous determination of the labour share which is very influential in price-setting behaviour in the NKPC. This observation notwithstanding, we can safely conclude that our estimates can be employed in a wide variety of closed and open economy models which are nested within our general specification. 
Table 1: GMM Estimates for the G-7 (Mark-up=10\%)

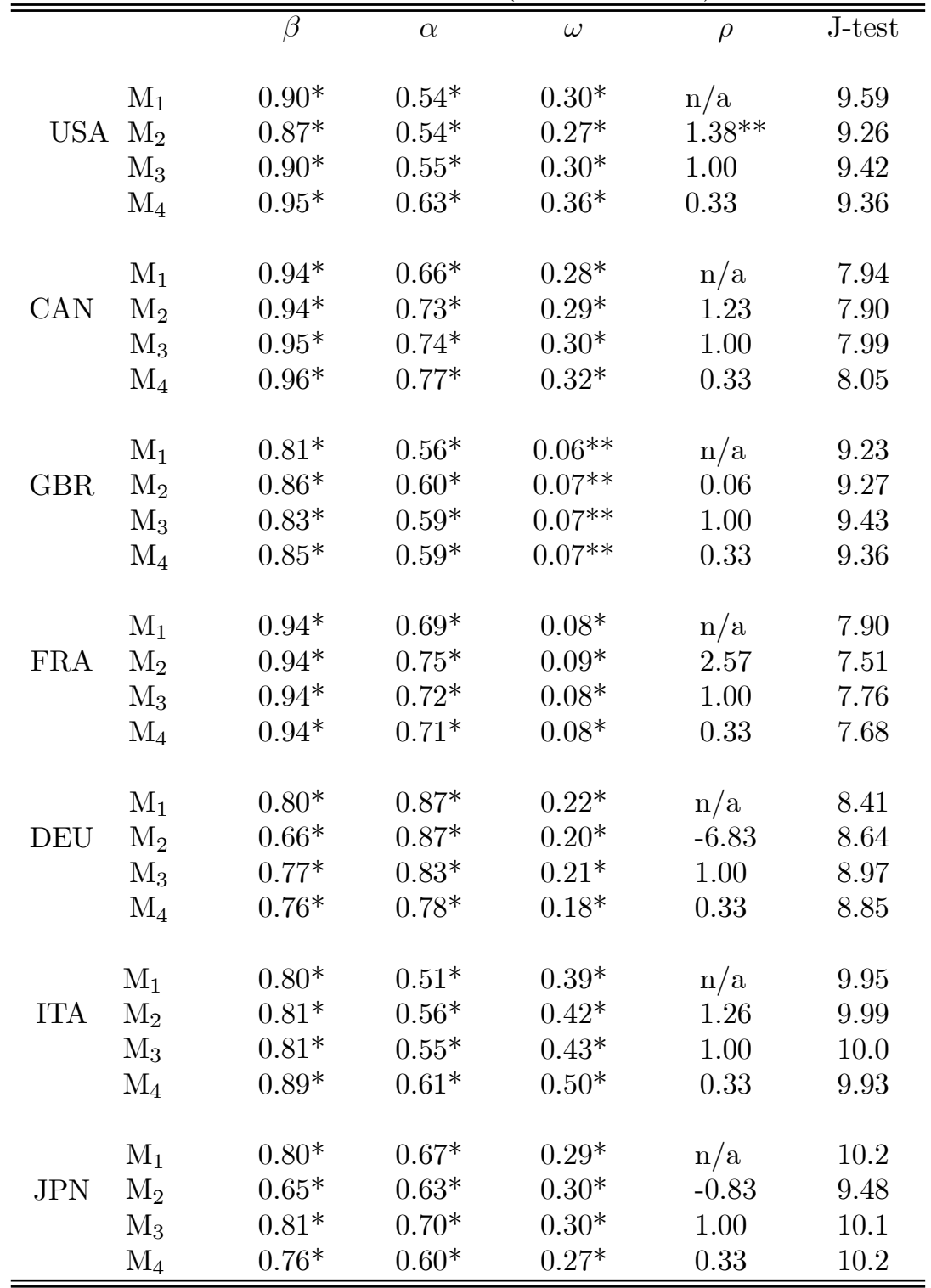

Notes: (i) USA, CAN, GBR, FRA, DEU, ITA and JPN are abbreviations for the US, Canada, UK, France, Germany, Italy and Japan respectively; (ii) * and ** indicates a significant t-test at the 1 and 5\% levels respectively; (iii) the t-tests are calculated using heteroscedastic consistent standard errors; (iv) all t-tests are based on the null hypothesis of the estimated parameter being equal to zero (except for $\rho$ which tests away from a null of unity); (v) in $\mathrm{M}_{3}$ and $\mathrm{M}_{4}$ the parameter $\rho$ is restricted to unity and one-third respectively. 
Table 2: T-tests Equality of the $\alpha^{\prime} s$

\begin{tabular}{cccc}
\hline \hline & $\mathrm{M}_{2}-\mathrm{M}_{1}$ & $\mathrm{M}_{3}-\mathrm{M}_{1}$ & $\mathrm{M}_{4}-\mathrm{M}_{1}$ \\
USA & $0.0003(0.008)$ & $0.010(0.27)$ & $0.091(1.89)$ \\
CAN & $0.063(0.64)$ & $0.073(0.78)$ & $0.111(1.16)$ \\
GBR & $0.046(1.21)$ & $0.032(1.07)$ & $0.035(1.27)$ \\
FRA & $0.060(0.86)$ & $0.024(0.60)$ & $0.017(0.36)$ \\
DEU & $-0.004(-0.04)$ & $-0.039(-0.76)$ & $-0.090(-2.29)^{* *}$ \\
ITA & $0.052(1.18)$ & $0.044(1.00)$ & $0.098(1.70)$ \\
JPN & $-0.039(-0.49)$ & $0.032(0.36)$ & $-0.069(-1.11)$ \\
\hline \hline
\end{tabular}

Note: the above figures are the parameter differences across models and the numbers in parentheses are t-statistics.

Table 3: T-Tests for Equality of the $\omega^{\prime} s$

\begin{tabular}{cccc}
\hline \hline & $\mathrm{M}_{1} \mathrm{v} \mathrm{M}_{2}$ & $\mathrm{M}_{1} \mathrm{v} \mathrm{M}_{3}$ & $\mathrm{M}_{1} \mathrm{v} \mathrm{M} \mathrm{M}_{4}$ \\
USA & $-0.034(-0.77)$ & $-0.003(-0.06)$ & $0.063(1.25)$ \\
CAN & $0.014(0.17)$ & $0.020(0.29)$ & $0.042(0.63)$ \\
GBR & $0.008(0.26)$ & $0.002(0.09)$ & $0.005(0.16)$ \\
FRA & $0.007(0.21)$ & $0.003(0.09)$ & $0.004(0.14)$ \\
DEU & $-0.026(-0.44)$ & $-0.018(-0.31)$ & $-0.048(-0.96)$ \\
ITA & $0.023(0.43)$ & $0.037(0.86)$ & $0.108(2.37)^{*}$ \\
JPN & $0.010(0.17)$ & $0.013(0.24)$ & $-0.019(-0.43)$ \\
\hline \hline
\end{tabular}

Note: the above figures are the parameter differences across models and the numbers in parentheses are t-statistics.

Table 4: Wald Tests for $\rho$

\begin{tabular}{ccc}
\hline \hline & $\rho=1$ & $\rho=0.33$ \\
USA & $4.48^{* *}$ & $34.1^{*}$ \\
CAN & 0.04 & 0.66 \\
GBR & 2.51 & 0.34 \\
FRA & 0.37 & 0.75 \\
DEU & 0.89 & 0.75 \\
ITA & 0.49 & $6.11^{* *}$ \\
JPN & 2.99 & 1.21 \\
\hline \hline
\end{tabular}

Note: the above tests are distributed

$\chi^{2}(1)$. The critical values at the 1

and $5 \%$ levels are 6.63 and 3.84

respectively.

As a check on the robustness of our results, Tables 5-8 (see Appendix III) reports the same statistics as Tables 1-4 but for a much higher mark-up of $40 \%$. Raising this mark-up tends to increase the estimates of nominal inertia implied by the $\alpha$ parameter. However, again these results are not materially affected by introducing the open economy effects outlined in this paper. Finally, we also imposed constant ratios of imported intermediate goods to GDP rather than 
allow them to trend upwards over time, and found the estimates reported in the paper to be robust to this change ${ }^{11}$.

\section{Conclusions}

In this paper we developed a model of firms' pricing behaviour in the context of an open economy model, where imperfectly competitive firms sell their products both at home and abroad, and produce their good by using a combination of local labour, capital and imported intermediate goods. This allows us to introduce various terms of trade effects influencing the firm's pricing decision, in addition to labour costs which dominate most closed-economy specifications of the NKPC. We assumed that firms were subject to the constraints on the timing of their price changes in the form of Calvo(1983) contracts, such that they can only change price after a random interval of time has passed. We also allow firms to operate two types of pricing policy. The first is where firms attempt to maximise the discounted value of profits, while under the second a firm may choose to follow a simple rule of thumb which updates prices in line with observed price changes and inflation. This setup gave rise to a hybrid open economy NKPC which nests all of the specifications adopted in empirical work on individual countries. We then estimated this specification for the G7 economies.

Our empirical results suggest that the US, Canada and UK economies suffer from less price inertia than European members of the G7 and Japan. A notable exception to this rule is Italy, although here the proportion of backward-looking price setters is the highest in the G7, possibly suggesting that the relatively frequent price adjustment in Italy is a result of indexation mechanisms rather than more conventional notions of price flexibility. Another interesting result is that firms in countries where the frequency of price change is greatest are more likely to employ backward-looking rules of thumb. This probably reflects the fact that the costs of failing to set a price optimally are lower when that price is unlikely to remain in place for long.

Another key finding is that these results hold true whether we adopt a closed economy or an open economy specification of the Phillips curve, i.e. our estimates of model parameters are not significantly different under these alternative specifications. Additionally, we found that we could not reject the restriction that the elasticity of substitution between imported goods and labour in production was unity (i.e. the Cobb-Douglas case) for all the G7 economies, except the US. Again, imposing this parameter restriction (even for the US) did not materially affect estimates of the degree of nominal inertia in the G7. This suggests that our parameter estimates can be used in a wide-variety of theoretical and simulation work, both in closed and open economy contexts, and with a variety of production functions. An obvious extension of our research would be

\footnotetext{
${ }^{11}$ To preserve space these results are not reported here but will be made available on request from the authors.
} 
to incorporate the open economy NKPC into a general equilibrium framework, such as those employed in the New Open Economy Macroeconomics, so that the quantitative importance of an endogenous labour share on price setting and in turn the effectiveness of monetary and fiscal policy could be established. 


\section{References}

[1] Balakrishnan, R. and J. D. Lopez-Salido (2001), 'Understanding UK Inflation: The Role of Openness', mimeograph, Banco de Espana.

[2] Calvo, G. (1983), 'Staggered Prices in a Utility Maximising Framework', Journal of Monetary Economics, 12(3), pp 383-398.

[3] Galí, J. and M. Gertler (1999), 'Inflation Dynamics: A Structural Econometric Analysis', Journal of Monetary Economics, 44, pp195-222.

[4] Galí, J., M. Gertler and J. D. Lopez-Salido (2001), 'European Inflation Dynamics', European Economic Review 45, pp 1237-1270.

[5] Gali, J. and J. D. Lopez-Salido (2001), 'A New Phillips Curve for Spain', mimeograph, Banco de Espana.

[6] Gagnon, E. and H. Kahn (2001), 'New Phillips Curves with Alternative Marginal Cost Measures for Canada, the United States and the Euro Area', mimeo, Bank of Canada.

[7] Goodfriend, M. and R. King (1997), 'The New Neoclassical Synthesis and the Role of Monetary Policy', NBER Macroeconomics Annual 1997, pp231282 .

[8] Hall, B. and Cummins, C. (1999) TSP Version 4.5, TSP International.

[9] Hansen, L.P. (1992), 'Large Sample Properties of Generalized Method of Moments Estimators', Econometrica, 50, pp 1029-54.

[10] Mankiw, N. G. (2000), 'The Inexorable and Mysterious Trade-off Between Inflation and Unemployment', NBER working Paper No. 7884

[11] Mankiw, N. G. and R. Reis (2001), 'Sticky Information versus Sticky Prices: A Proposal to Replace the New Keynesian Phillips Curve', NBER Working Paper No. 8290.

[12] McCallum, B. T. (2001), 'Inflation Targeting and the Liquidity Trap', NBER Working Paper No. 8225.

[13] Sbordone, A. M. (2002), 'Prices and Unit Labour Costs: A New Test of Price Stickiness', Journal of Monetary Economics, No. 49, pp 265-292.

[14] Sims, C. A. (1998), 'Stickiness', Carnegie-Rochester Conference Series on Public Policy 49, pp317-356. 


\section{Appendix I - Operationalising the Open Economy NKPC}

To transform our Phillips curve to a form more appropriate for estimation and to facilitate comparability with existing studies it is necessary to relate the open economy measure of marginal cost to the typical closed economy proxy, the ratio of labour income to GDP. To do so recall that average firm output in the presence of intermediate good inputs is given by,

$$
\widetilde{y}_{t}=y_{t}+\frac{p_{t}^{f}}{p_{t}^{d}} m_{t}^{f}
$$

where $\widetilde{y}_{t}$ is average firm output and and $y_{t}$ is real GDP. After log-linearisation this implies,

$$
\widehat{\widetilde{y}}_{t}=\frac{\bar{p}^{d} \bar{y}}{\bar{p}^{d} \bar{y}+\bar{p}^{f} \bar{m}^{f}} \widehat{y}_{t}+\frac{\bar{p}^{f} \bar{m}^{f}}{\bar{p}^{d} \bar{y}+\bar{p}^{f} \bar{m}^{f}}\left(\widehat{m}_{t}^{f}+\widehat{p}_{t}^{f}-\widehat{p}_{t}^{d}\right) .
$$

Substituting the expression for the optimal level of imported intermediate goods,(12), and solving for average firm output gives,

$\widehat{\widetilde{y}}_{t}=\frac{\bar{p}^{d} \bar{y}}{\bar{p}^{d} \bar{y}+(1-\psi) \bar{p}^{f} \bar{m}^{f}} \widehat{y}_{t}+\frac{\bar{p}^{f} \bar{m}^{f}}{\bar{p}^{d} \bar{y}+(1-\psi) \bar{p}^{f} \bar{m}^{f}}\left(\frac{\rho \alpha_{N}\left(\bar{w}^{f} \frac{\alpha_{m}}{\alpha_{N}}\right)^{1-\rho}}{\alpha_{N}\left(\bar{w}^{f} \frac{\alpha_{m}}{\alpha_{N}}\right)^{1-\rho}+\alpha_{m}} \widehat{w}_{t}^{f}+\widehat{p}_{t}^{f}-\widehat{p}_{t}^{d}\right)$.

This allows us to rewrite the Phillips curve as,

$$
\begin{aligned}
\widehat{\pi}_{t}^{d}= & \frac{\beta \alpha}{\lambda} E_{t} \widehat{\pi}_{t+1}^{d}+\frac{\omega}{\lambda} \widehat{\pi}_{t-1}^{d}+\frac{(1-\omega)(1-\alpha)(1-\alpha \beta)}{(1+(\psi-1) \theta) \lambda}\left(\frac{\bar{w}}{\left(\bar{w}+\frac{\bar{p}^{f}}{\bar{P}}\left(\bar{w}^{f} \frac{\alpha_{m}}{\alpha_{N}}\right)^{\rho}\right)} \widehat{w}_{t}\right. \\
& +\frac{\frac{\bar{p}^{f}}{\bar{P}}\left(\bar{w}^{f} \frac{\alpha_{m}}{\alpha_{N}}\right)^{\rho}}{\left(\bar{w}+\frac{\bar{p}^{f}}{\bar{P}}\left(\bar{w}^{f} \frac{\alpha_{m}}{\alpha_{N}}\right)^{\rho}\right)}\left(\widehat{p}_{t}^{f}-\widehat{P}_{t}\right)+(\psi-1)\left(\frac{\bar{p}^{d} \bar{y}}{\bar{p}^{d} \bar{y}+(1-\psi) \bar{p}^{f} \bar{m}^{f}} \widehat{y}_{t} \quad(37)\right. \\
& \left.\left.+\frac{\bar{p}^{f} \bar{m}^{f}}{\bar{p}^{d} \bar{y}+(1-\psi) \bar{p}^{f} \bar{m}^{f}}\left(\frac{\rho \alpha_{N}\left(\bar{w}^{f} \frac{\alpha_{m}}{\alpha_{N}}\right)^{1-\rho}}{\alpha_{N}\left(\bar{w}^{f} \frac{\alpha_{m}}{\alpha_{N}}\right)^{1-\rho}+\alpha_{m}} \widehat{w}_{t}^{f}+\widehat{p}_{t}^{f}-\widehat{p}_{t}^{d}\right)\right)+\widehat{P}_{t}-\widehat{p}_{t}^{d}\right) .
\end{aligned}
$$

Another way of rewriting this is in terms of the labour share variable, e.g.

$$
\widehat{s}_{t}=\widehat{W}_{t}-\widehat{P}_{t}+\widehat{N}_{t}-\widehat{y}_{t}-(1-\chi)\left(\widehat{p}_{t}^{d}-\widehat{p}_{t}^{f}\right) .
$$

Substituting for the first-order condition for labour supply and using the definition of consumer prices yields,

$$
\widehat{s}_{t}=\widehat{W}_{t}+\psi \widehat{\widetilde{y}}_{t}-\frac{\rho \alpha_{m}\left(\bar{w}^{f} \frac{\alpha_{m}}{\alpha_{N}}\right)^{\rho-1}}{\alpha_{N}+\alpha_{m}\left(\bar{w}^{f} \frac{\alpha_{m}}{\alpha_{N}}\right)^{\rho-1}} \widehat{w}_{t}^{f}-\widehat{p}_{t}^{d}-\widehat{y}_{t}
$$


Substituting for the average firm output yields,

$$
\begin{aligned}
\widehat{s}_{t}= & \widehat{W}_{t}+\psi\left(\frac{\bar{p}^{d} \bar{y}}{\bar{p}^{d} \bar{y}+(1-\psi) \bar{p}^{f} \bar{m}^{f}} \widehat{y}_{t}\right. \\
& \left.+\frac{\bar{p}^{f} \bar{m}^{f}}{\bar{p}^{d} \bar{y}+(1-\psi) \bar{p}^{f} \bar{m}^{f}}\left(\frac{\rho \alpha_{N}\left(\bar{w}^{f} \frac{\alpha_{m}}{\alpha_{N}}\right)^{1-\rho}}{\alpha_{N}\left(\bar{w}^{f} \frac{\alpha_{m}}{\alpha_{N}}\right)^{1-\rho}+\alpha_{m}} \widehat{w}_{t}^{f}+\widehat{p}_{t}^{f}-\widehat{p}_{t}^{d}\right)\right) \\
& -\frac{\rho \alpha_{m}\left(\bar{w}^{f} \frac{\alpha_{m}}{\alpha_{N}}\right)^{\rho-1}}{\alpha_{N}+\alpha_{m}\left(\bar{w}^{f} \frac{\alpha_{m}}{\alpha_{N}}\right)^{\rho-1}} \widehat{w}_{t}^{f}-\widehat{p}_{t}^{d}-\widehat{y}_{t} .
\end{aligned}
$$

Collecting terms,

$$
\begin{aligned}
\widehat{s}_{t}= & (\psi-1)\left(\frac{\bar{p}^{d} \bar{y}+\bar{p}^{f} \bar{m}^{f}}{\bar{p}^{d} \bar{y}+(1-\psi) \bar{p}^{f} \bar{m}^{f}} \widehat{y}_{t}\right. \\
& +\left(1+\frac{\psi \bar{p}^{f} \bar{m}^{f}}{\bar{p}^{d} \bar{y}+(1-\psi) \bar{p}^{f} \bar{m}^{f}} \frac{\rho \alpha_{n}\left(\bar{w}^{f} \frac{\alpha_{m}}{\alpha_{N}}\right)^{1-\rho}}{\alpha_{n}\left(\bar{w}^{f} \frac{\alpha_{m}}{\alpha_{N}}\right)^{1-\rho}+\alpha_{m}}-\frac{\rho \alpha_{m}\left(\bar{w}^{f} \frac{\alpha_{m}}{\alpha_{N}}\right)^{\rho-1}}{\alpha_{N}+\alpha_{m}\left(\bar{w}^{f} \frac{\alpha_{m}}{\alpha_{N}}\right)^{\rho-1}}\right) \widehat{W}_{t} \\
& +\left(-\frac{\psi \bar{p}^{f} \bar{m}^{f}}{\bar{p}^{d} \bar{y}+(1-\psi) \bar{p}^{f} \bar{m}^{f}} \frac{\rho \alpha_{n}\left(\bar{w}^{f} \frac{\alpha_{m}}{\alpha_{N}}\right)^{1-\rho}}{\alpha_{n}\left(\bar{w}^{f} \frac{\alpha_{m}}{\alpha_{N}}\right)^{1-\rho}+\alpha_{m}}\right. \\
& \left.+\frac{\rho \alpha_{m}\left(\bar{w}^{f} \frac{\alpha_{m}}{\alpha_{N}}\right)^{\rho-1}}{\alpha_{N}+\alpha_{m}\left(\bar{w}^{f} \frac{\alpha_{m}}{\alpha_{N}}\right)^{\rho-1}}+\frac{\psi \bar{p}^{f} \bar{m}^{f}}{\bar{p}^{d} \bar{y}+(1-\psi) \bar{p}^{f} \bar{m}^{f}}\right) \widehat{p}_{t}^{f} \\
& +\left(-\frac{\psi \bar{p}^{f} \bar{m}^{f}}{\bar{p}^{d} \bar{y}+(1-\psi) \bar{p}^{f} \bar{m}^{f}}-1\right) \widehat{p}_{t}^{d}
\end{aligned}
$$

Substituting this into the Phillips curve yields,

$$
\begin{aligned}
& \widehat{\pi}_{t}^{d}=\frac{\beta \alpha}{\lambda} E_{t} \widehat{\pi}_{t+1}^{d}+\frac{\omega}{\lambda} \widehat{\pi}_{t-1}^{d}+\frac{(1-\omega)(1-\alpha)(1-\alpha \beta)}{(1+(\psi-1) \theta) \lambda}\left(\widehat{s}_{t}\right. \\
& -(\psi-1)\left(\frac{\bar{p}^{d} \bar{y}+\bar{p}^{f} \bar{m}^{f}}{\bar{p}^{d} \bar{y}+(1-\psi) \bar{p}^{f} \bar{m}^{f}} \widehat{y}_{t}\right) \\
& -\left(\frac{(1-\rho) \frac{\bar{p}^{f}}{\bar{P}}\left(\bar{w}^{f} \frac{\alpha_{m}}{\alpha_{N}}\right)^{\rho}}{\left(\bar{w}+\frac{\bar{p}^{f}}{\bar{P}}\left(\bar{w}^{f} \frac{\alpha_{m}}{\alpha_{N}}\right)^{\rho}\right)}+\frac{\bar{p}^{f} \bar{m}^{f}}{\bar{p}^{d} \bar{y}+(1-\psi) \bar{p}^{f} \bar{m}^{f}} \frac{\rho \alpha_{N}\left(\bar{w}^{f} \frac{\alpha_{m}}{\alpha_{N}}\right)^{1-\rho}}{\alpha_{N}\left(\bar{w}^{f} \frac{\alpha_{m}}{\alpha_{N}}\right)^{1-\rho}+\alpha_{m}}\right)\left(\widehat{W}-\widehat{p}_{t}^{f}\right) \\
& \left.+\frac{\bar{p}^{f} \bar{m}^{f}}{\bar{p}^{d} \bar{y}+(1-\psi) \bar{p}^{f} \bar{m}^{f}}\left(\widehat{p}_{t}^{d}-\widehat{p}_{t}^{f}\right)\right)
\end{aligned}
$$

This can be rewritten by noting the following relationships. Consider the share of labour costs relative to labour and intermediate goods costs,

$$
\frac{\overline{W N}}{\overline{W N}+\bar{p}^{f} \bar{m}^{f}}
$$


Dividing through by $\bar{N}$ and utilising the equation for the cost-minimising combination of labour and imported intermediate goods yields,

$$
\frac{\bar{w}}{\bar{w}+\frac{\bar{p}^{f}}{\bar{P}}\left(\bar{w}^{f} \frac{\alpha_{m}}{\alpha_{n}}\right)^{\rho}} .
$$

Therefore, since labour share data, and the ratio of imported intermediate goods to GDP, $\frac{\bar{p}^{f} \bar{m}^{f}}{\bar{p}^{d} \bar{y}}$ is readily available, we can construct this ratio as, $\frac{\bar{s}}{\bar{s}+\frac{\bar{s} f}{\bar{p}^{d} f}}=$ $\frac{\overline{W N}}{\overline{W N+\bar{p}^{f} \bar{m}^{f}}}=\frac{\bar{w}}{\bar{w}+\frac{\bar{p}^{f}}{P}\left(\bar{w}^{f} \frac{\alpha_{m}}{\alpha_{n}}\right)^{\rho}}=\frac{\alpha_{N}\left(\bar{w}^{f} \frac{\alpha_{m}}{\alpha_{N}}\right)^{1-\rho}}{\alpha_{N}\left(\bar{w}^{f} \frac{\alpha_{m}}{\alpha_{N}}\right)^{1-\rho}+\alpha_{m}}$ and re-write the Phillips curve as equation (29) in the main text.

\section{Appendix II - Data Sources}

The following data were obtained from the OECD's Business Sector Database: real GDP (market prices), $y$; GDP (market price) deflator, $p^{d}$; nominal compensation of employees, $W N$; nominal wage per employee, $W$; real imports of goods and services, $M^{f}$; import price deflator, $p^{f}$; and employment, $N$. The data run from 1960 quarter 1 to 1999 quarter 4 and are quoted in local currency units. The world commodity price index, $c^{p}$ was obtained from the IMF's International Financial Statistics database. The data used to calculate the average value of imported goods used in production as a share of total imports were obtained from CEPII's CHELEM (Harmonised Accounts on Trade and the World Economy) database. The 71 product categories available from 1967 to 1998 have been classified by CEPII into the following sectoral stages of production: primary, basic manufacturing, intermediate goods, equipment goods, mixed products and consumption goods and 'not elsewhere specified' products. To calculate our measure of average value of imported goods used in production as a share of total imports we include primary, basic manufacturing, intermediate goods and equipment goods in the numerator. The figures for the G-7 by country are: $\mathrm{USA}=0.609, \mathrm{CAN}=0.705, \mathrm{GBR}=0.634, \mathrm{FRA}=0.678, \mathrm{DEU}=0.647$, $\mathrm{ITA}=0.689$ and $\mathrm{JPN}=0.740$. 


\section{Appendix III - Results}

Table 5: GMM Estimates for the G-7 (Mark-up=40\%)

\begin{tabular}{|c|c|c|c|c|c|c|}
\hline & & $\overline{\overline{\beta \beta}}$ & $\overline{\alpha \alpha}$ & $\bar{\omega}$ & $\overline{\overline{\rho \rho}}$ & $\overline{\text { J-test }}$ \\
\hline \multirow{4}{*}{ USA } & $\mathrm{M}_{1}$ & $0.89^{*}$ & $0.64^{*}$ & $0.35^{*}$ & $\mathrm{n} / \mathrm{a}$ & 9.58 \\
\hline & $\mathrm{M}_{2}$ & $0.88^{*}$ & $0.64^{*}$ & $0.31^{*}$ & 1.33 & 9.30 \\
\hline & $\mathrm{M}_{3}$ & $0.90^{*}$ & $0.65^{*}$ & $0.34^{*}$ & 1.00 & 9.39 \\
\hline & $\mathrm{M}_{4}$ & $0.95^{*}$ & $0.71^{*}$ & $0.40^{*}$ & 0.33 & 9.36 \\
\hline \multirow{4}{*}{ CAN } & $\mathrm{M}_{1}$ & $0.94^{*}$ & $0.74 *$ & $0.31^{*}$ & $\mathrm{n} / \mathrm{a}$ & 7.94 \\
\hline & $\mathrm{M}_{2}$ & $0.95^{*}$ & $0.81^{*}$ & $0.33^{*}$ & 1.10 & 7.96 \\
\hline & $\mathrm{M}_{3}$ & $0.95^{*}$ & $0.82^{*}$ & $0.33^{*}$ & 1.00 & 8.01 \\
\hline & $\mathrm{M}_{4}$ & $0.96^{*}$ & $0.84^{*}$ & $0.34^{*}$ & 0.33 & 8.05 \\
\hline \multirow{4}{*}{ GBR } & $\mathrm{M}_{1}$ & $0.82^{*}$ & $0.66^{*}$ & $0.08^{* *}$ & $\mathrm{n} / \mathrm{a}$ & 9.25 \\
\hline & $\mathrm{M}_{2}$ & $0.87^{*}$ & $0.69^{*}$ & $0.08^{* *}$ & 0.10 & 9.31 \\
\hline & $\mathrm{M}_{3}$ & $0.85^{*}$ & $0.68^{*}$ & $0.08^{* *}$ & 1.00 & 9.48 \\
\hline & $\mathrm{M}_{4}$ & $0.86^{*}$ & $0.68^{*}$ & $0.08^{* *}$ & 0.33 & 9.41 \\
\hline \multirow{4}{*}{ FRA } & $\mathrm{M}_{1}$ & $0.94^{*}$ & $0.77^{*}$ & $0.09^{*}$ & $\mathrm{n} / \mathrm{a}$ & 7.89 \\
\hline & $\mathrm{M}_{2}$ & $0.95^{*}$ & $0.82^{*}$ & $0.09^{*}$ & 2.55 & 7.48 \\
\hline & $\mathrm{M}_{3}$ & $0.95^{*}$ & $0.79^{*}$ & $0.09 *$ & 1.00 & 7.71 \\
\hline & $\mathrm{M}_{4}$ & $0.95^{*}$ & $0.79^{*}$ & $0.09^{*}$ & 0.33 & 7.63 \\
\hline \multirow{4}{*}{ DEU } & $\mathrm{M}_{1}$ & $0.80^{*}$ & $0.92^{*}$ & $0.24^{*}$ & $\mathrm{n} / \mathrm{a}$ & 8.41 \\
\hline & $\mathrm{M}_{2}$ & $0.66^{*}$ & $0.93^{*}$ & $0.21^{*}$ & -8.74 & 8.64 \\
\hline & $\mathrm{M}_{3}$ & $0.76^{*}$ & $0.91^{*}$ & $0.23^{*}$ & 1.00 & 8.99 \\
\hline & $\mathrm{M}_{4}$ & $0.76^{*}$ & $0.86^{*}$ & $0.20^{*}$ & 0.33 & 8.86 \\
\hline \multirow{4}{*}{ ITA } & $\mathrm{M}_{1}$ & $0.78^{*}$ & $0.61^{*}$ & $0.47^{*}$ & $\mathrm{n} / \mathrm{a}$ & 9.98 \\
\hline & $\mathrm{M}_{2}$ & $0.80^{*}$ & $0.66^{*}$ & $0.49^{*}$ & 1.24 & 9.98 \\
\hline & $\mathrm{M}_{3}$ & $0.80^{*}$ & $0.66^{*}$ & $0.50^{*}$ & 1.00 & 10.1 \\
\hline & $\mathrm{M}_{4}$ & $0.87^{*}$ & $0.69 *$ & $0.57^{*}$ & 0.33 & 9.95 \\
\hline \multirow{4}{*}{ JPN } & $\mathrm{M}_{1}$ & $0.80^{*}$ & $0.76^{*}$ & $0.33^{*}$ & $\mathrm{n} / \mathrm{a}$ & 10.2 \\
\hline & $\mathrm{M}_{2}$ & $0.64^{*}$ & $0.73^{*}$ & $0.34^{*}$ & -0.88 & 9.48 \\
\hline & $\mathrm{M}_{3}$ & $0.80^{*}$ & $0.80^{*}$ & $0.34^{*}$ & 1.00 & 10.1 \\
\hline & $\mathrm{M}_{4}$ & $0.76^{*}$ & $0.71^{*}$ & $0.31^{*}$ & 0.33 & 10.2 \\
\hline
\end{tabular}

Notes: (i) USA, CAN, GBR, FRA, DEU, ITA and JPN are abbreviations for the US, Canada, UK, France, Germany, Italy and Japan respectively; (ii) * and ** indicates a significant t-test at the 1 and $5 \%$ levels respectively; (iii) the t-tests are calculated using heteroscedastic consistent standard errors; (iv) all t-tests are based on the null hypothesis of the estimated parameter being equal to zero (except for $\rho$ which tests away from a null of unity); (v) in $\mathrm{M}_{3}$ and $\mathrm{M}_{4}$ the parameter $\rho$ is restricted to unity and one-third respectively. 
Table 6: T-Tests for Equality of the $\alpha^{\prime} s$

\begin{tabular}{cccc}
\hline \hline & $\mathrm{M}_{2}-\mathrm{M}_{1}$ & $\mathrm{M}_{3}-\mathrm{M}_{1}$ & $\mathrm{M}_{4}-\mathrm{M}_{1}$ \\
USA & $0.005(0.17)$ & $0.009(0.27)$ & $0.069(1.65)$ \\
CAN & $0.070(0.76)$ & $0.070(0.89)$ & $0.099(1.22)$ \\
GBR & $0.031(0.96)$ & $0.022(0.82)$ & $0.022(0.87)$ \\
FRA & $0.046(0.81)$ & $0.017(0.54)$ & $0.012(0.30)$ \\
DEU & $0.011(0.14)$ & $-0.009(-0.20)$ & $-0.059(-1.75)$ \\
ITA & $0.050(1.32)$ & $0.041(1.10)$ & $0.078(1.59)$ \\
JPN & $-0.031(-0.45)$ & $0.037(0.45)$ & $-0.055(-0.99)$ \\
\hline \hline
\end{tabular}

$\overline{\overline{\text { Note: }} \text { the above figures are the parameter differences across }}$ models and the numbers in parentheses are t-statistics.

Table 7: T-Tests for Equality of the $\omega^{\prime} s$

\begin{tabular}{cccc}
\hline \hline & $\mathrm{M}_{2}-\mathrm{M}_{1}$ & $\mathrm{M}_{3}-\mathrm{M}_{1}$ & $\mathrm{M}_{4}-\mathrm{M}_{1}$ \\
USA & $-0.035(-0.69)$ & $-0.007(-0.16)$ & $0.053(0.95)$ \\
CAN & $0.016(0.18)$ & $0.017(0.23)$ & $0.035(0.49)$ \\
GBR & $0.004(0.12)$ & $0.022(-0.03)$ & $0.0009(0.03)$ \\
FRA & $0.005(0.15)$ & $0.002(0.05)$ & $0.003(0.10)$ \\
DEU & $-0.024(-0.39)$ & $-0.005(-0.07)$ & $-0.038(-0.04)$ \\
ITA & $0.022(0.40)$ & $0.036(0.84)$ & $0.100(2.34)^{* *}$ \\
JPN & $0.016(0.24)$ & $0.015(0.25)$ & $-0.012(-0.24)$ \\
\hline \hline
\end{tabular}

Note: the above figures are the parameter differences across models and the numbers in parentheses are t-statistics.

Table 8: Wald Tests for $\rho$

\begin{tabular}{ccc}
\hline \hline & $\rho=1$ & $\rho=0.33$ \\
USA & 3.15 & $28.3^{*}$ \\
CAN & 0.005 & 0.26 \\
GBR & 2.73 & 0.42 \\
FRA & 0.34 & 0.70 \\
DEU & 0.54 & 0.46 \\
ITA & 0.37 & $5.27^{* *}$ \\
JPN & 3.54 & 1.48 \\
\hline \hline
\end{tabular}

Note: the above tests are distributed

$\chi^{2}(1)$. The critical values at the 1

and $5 \%$ levels are 6.63 and 3.84

respectively. 